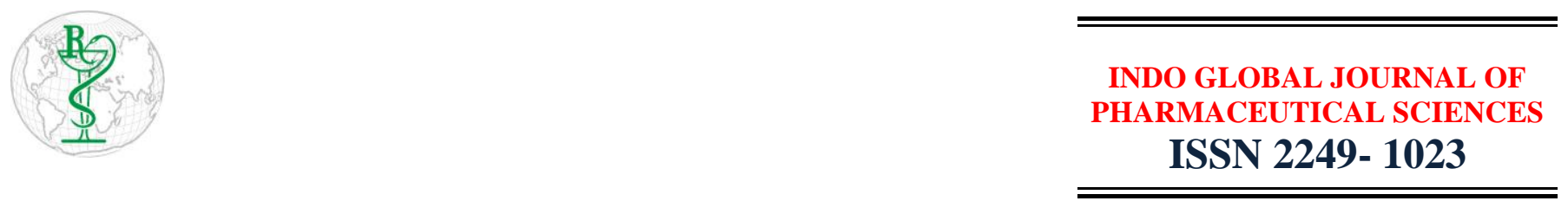

\title{
A Review: Therapeutic Effects of Hibiscus rosa sinensis Linn.
}

\begin{tabular}{l} 
Received: \\
01.03.2019 \\
Accepted: \\
25.03.2019 \\
Keywords \\
Medicinal Plants; \\
Herbal Products; \\
Natural \\
Medicines. \\
\hline
\end{tabular}

\author{
Sarabjit Singh *, Jagjit Singh \\ Sri Sai College of Pharmacy, Manawala, Amritsar-143115, Punjab, India
}

Address for Correspondence: Sarabjit Singh
ABSTRACT: The natural plant products are widely used nowadays because of increasing the burden of diseases. Hibiscus rosa sinensis Linn. (Family Malvaceae) is a plant which is widely distributed throughout the world. Its leaves, barks, roots and flowers have been used in the Indian traditional system as medicine to treat various diseases. Various research studies proved that the different parts of Hibiscus rosa sinensis plants possesses Antioxidant, Antimicrobial, Antidiabetic, Antiulcer, Hepatoprotective, Antifertility, Antigenotoxic and Antiinflammatory properties, which helps in treatment of many diseases. Hibiscus rosa sinensis has been used in many herbal mix and drinks. Many research studies conducted in animal modal evaluate Hibiscus rosa sinensis flowers and leaves as antidiabetic and antioxidant compounds. This review attempt to highlight the therapeutic application of Hibiscus rosa sinensis. (C) 2019 iGlobal Research and Publishing Foundation. All rights reserved.

Cite this article as: Singh, S.; Singh, J. A Review: Therapeutic Effects of Hibiscus rosa sinensis Linn. Indo Global J. Pharm. Sci., 2019; 9(2Suppl.): 159. DOI: http://doi.org/10.35652/IGJPS.2019.92S57.

Indo Global Journal of Pharmaceutical Sciences( ISSN 2249 1023; CODEN- IGJPAI; NLM ID: 101610675) indexed and abstracted in CrossRef (DOI Enabling), UGC CARE Journal List, EMBASE(Elsevier), National Library of Medicine (NLM) Catalog, ResearchGate, Publons, CAS (ACS), Index Copernicus, Google Scholar and many more. For further details, visit http://iglobaljournal.com

This is a special issue as an outcome of 'RAPSCON-2019' sponsored by APTI and organized by Sri Sai College of Pharmacy, Manawala, Amritsar, Punjab, India. Relaxation offered in journal format. 